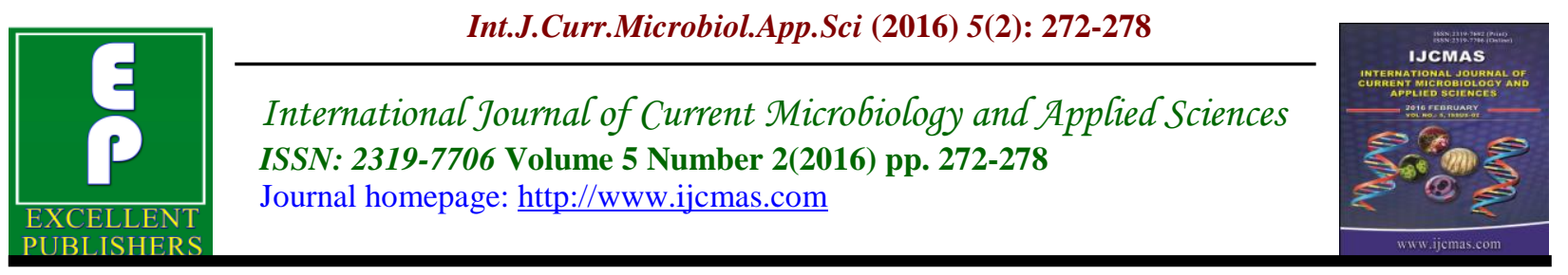

Original Research Article

doi: http://dx.doi.org/10.20546/ijcmas.2016.502.031

\title{
Microbial Vaginitis in Reproductive Women of Silk city of South India
}

\author{
Karthika Jayakumar $^{1 *}$, Wills shiela ${ }^{2}$, S. Jayalakshmi ${ }^{1}$, \\ Sathya Pandurangan ${ }^{1}$ and M. Mohanambal ${ }^{2}$ \\ ${ }^{1}$ Department of Microbiology, Shri Sathya Sai Medical College and Research Institute \\ Kancheepuram (District), Tamilnadu, India \\ ${ }^{2}$ Department of O and G, Shri Sathya Sai Medical College and Research Institute, \\ Kancheepuram (District), Tamilnadu, India \\ *Corresponding author
}

\begin{abstract}
A B S T R A C T
Keywords

Trichomonas

vaginalis,

Culture,

Microscopy,

Vaginitis,

Silk city of

South India

Article Info

Accepted:

15 January 2016

Available Online:

10, February 2016

Vaginitis is caused by several microbial agents and non-infective irritants. It is usually associated with urethritis, dysperunia, dysmenorrhea and lower abdominal pain. Microbial agents are transmitted through sexual contact and unhygienic habits. Hence, this study is designed to rule out the incidence of Microbial agents in reproductive women by microscopy, staining \&culture. 100 patients after sensitization of the project were taken for this study Samples processed by microscopy, special staining and culture. The culture was performed with KUPFERBERG media. Out of 100 samples, 54 grew bacterial colonies, 30 were found to be positive for Trichomonas vaginalis, 2 for Candida albicans and the remaining 14 were having normal vaginal flora. The parasitic agents were found in 30 swabs by Giemsa stain. Preliminary wet mount microscopic examination revealed 15 cases to be positive. The analysis showed the correlation between bacterial and parasitic isolation, which was more common among sexually active female patients, which requires screening of patients in appropriate manner and treat accordingly to envisage a healthy quality life for the patients.
\end{abstract}

\section{Introduction}

Vaginitis is a known infectious disease caused by several microbial agents and noninfective irritants. The disease often involves vulva with mixed microbial agents. Therefore it is necessary to know the causative agents for patient care and management.
Vagina has mixed anaerobic and aerobic bacterial flora including Gardnerella vaginalis causing bacterial vaginosis. Infections with Clostridium perfringens typically after illegal abortions with non sterile instruments is also a well established entity (1). 
Genital tract Infections of women are well known in reproductive age group and they are the commonest problem that makes a lady to visit her gynecologist with vaginal discharge. This can happen due to bacterial, fungal and parasitic microbial agents. It is usually associated with urethritis, dysperunia, dysmenorrhea and lower abdominal pain.

Trichomonas vaginalis is an important cause for sexually transmitted infection in reproductive age group. It is the most prevalent non- viral, non -bacterial cause for genital tract infection. It can also co-exist with HIV, Herpes simplex viruses, and can enhance the risk of Human Papilloma virus infection in women (2).

This disease is caused by a pear shaped protozoan Trichomonas vaginalis, giving rise to frothy, foul- smelling discharge with vulvo- vaginal irritation and lower abdominal pain (3).

It can be an important cause for Pelvic inflammatory Disease (PID) leading to complications like infertility (4).

In this era of infertility and sterility with long married life, we decided to take up this study among reproductive age group, among our patients attending OG clinic in our hospital.

The main aim of this study includes to know the incidence of Microbial agents in reproductive age group women attending our hospital with Leucorrhoea. Demonstration of the agent by microscopy, staining techniques. Demonstration of the agent by culture techniques. To demonstrate the sensitivity of culture isolation from clinical samples. And also to correlate the clincal findings.

\section{Materials and Methods}

100 willing patients after sensitization of the project, who were attending our OG-OPD were taken for this study.

\section{Inclusion Criteria}

Willing, Reproductive age group women with vaginal discharge.

\section{Exclusion Criteria}

Elderely $(>50)$ and Young $(<15)$, other vaginitis conditions.

\section{Methods}

A total of 100 samples were taken from 100 willing, sexually active female patients with an age group ranging from 20-50 years (Table: 1).

The vaginal swab with appropriate labelling and duly filled up request form was received in microbiology laboratory and subjected for microscopic examination, specific special staining and culture inoculation and incubation.

\section{For Bacterial Etiology}

The swab was inoculated onto the Mac Conkey agar, Blood agar and Chocolate agar and incubated at $37^{\circ} \mathrm{C}$ for 48 hours. The culture plates were examined for colony growth and processed up to species level identification and antibiotic sensitivity performed as per NCCLS guidelines (5).

\section{For Parasitic STD}

The direct wet mount of vaginal smear was examined by direct microscopic examination. The culture was performed 
with KUPFERBERG media, though there are other media like, Feinberg, Whittington media. The swab was inoculated into the media incubated at $37^{\circ} \mathrm{C}$ for 7 days. The media was examined on $3^{\text {rd }}, 5^{\text {th }}, 7^{\text {th }}$ day and a strict aseptic precautions. Both wet mount microscopic and Giemsa staining were done (Table: 2)

The culture media and Giemsa stains were performed as per NCCLS guidelines (6).

\section{For fungal Causes}

Samples were inoculated onto Sabourauds Dextrose Agar and fungal colonies grown were identified up to species level.

\section{Results and Discussion}

Out of 100 samples, 54 samples grew bacterial colonies, 30 samples were found to be positive for Trichomonas vaginalis, 2 samples were positive for Candida albicans and the remaining 14 were having normal vaginal flora.

Among the bacterial colonies 52 samples had Gram negative bacterial growth and 2 samples had Gram positive cocci.

The parasitic agents were found to be positive in 30 swabs and identified by cuture and staining techniques by Giemsa stain. Preliminary wet mount microscopic examination revealed 15 cases to be positive (Table: 3).

2 samples yielded Candida albicans were found commonly in the $4^{\text {th }}$ decade of age group.

Both bacterial, parasitic agents were found commonly in the 3rd decade of age group (Table: 4).
Gram positive bacteria, isolates were MSSE (Methicillin Sensitive Staphylococcus epidermidis). The gram negative isolates had an array of bacteria: Escherichia coli, Klebsiella oxytoca and Klebsiella pneumonia, Pseudomonas aeruginosa and Acinetobacter baumanii.

The KUPFERBERG culture media was more fruitful as it yielded positive results on $3^{\text {rd }}$ day, $5^{\text {th }}$ day, and $7^{\text {th }}$ day prooving to be more specific and sensitive for clinching the parasitic STD agent.

Totally they were $30 \%$ culture positive for Trichomonas vaginalis, which was further confirmed by demonstration of the pear shaped protozoan by Giemsa staining technique (Pic:1)

The analysis of the 100 samples showed the following microbial profile (Table.5)

We got 54 bacterial vaginitis with heavy growth of Escherichia coli, Klebsiella oxytoca, Klebsiella pneumonia, Pseudomonas aeruginosa, Staphylococcus epidermidis and Acinetobacter baumanii. Their distribution is shown in (Table: 6)

The vaginal flora has complex microbiota with varying quantities and relative proportions (7).

There is an intricate balance among the microbes that maintains the normal vaginal flora. It is mainly dominated by the genus Lactobacillus that gives acidic $\mathrm{pH}$ to the vagina which guards against vaginitis.

When this $\mathrm{pH}$ gets altered, or colonization due to other bacteria and unhealthy sexual contact gives rise to vaginitis, which leads to vaginal discharge, urethritis, dysmenorrhea, dysperunia, lower abdominal pain and infertility. 
Table.1 Age Distribution of the Patients (100)

\begin{tabular}{|c|c|}
\hline $\begin{array}{c}\text { AGE GROUP } \\
\text { (YEARS) }\end{array}$ & PERCENTAGE \% \\
\hline $20-25$ & 20 \\
\hline $26-30$ & 21 \\
\hline $31-35$ & 30 \\
\hline $36-40$ & 15 \\
\hline $41-45$ & 07 \\
\hline $46-50$ & 04 \\
\hline $51 \&$ Above & 04 \\
\hline
\end{tabular}

Table.2 Culture Wet Mount Preparation and Giemsa Staining

\begin{tabular}{|c|c|c|c|}
\hline S:NO & INCUBATION & MICROSCOPY CULTURE & STAIN \\
& DAYS & & \\
\hline & $3^{\text {rd }}$ day & 15 & 15 \\
2 & $5^{\text {th }}$ day & 10 & 10 \\
3 & $7^{\text {th }}$ day & 5 & 5 \\
\hline
\end{tabular}

Table.3 Direct Wet Mount Preparation:

\begin{tabular}{|l|c|c|}
\hline Diagnosis & NO. positive for $T$. Vaginalis & NO. negative for $T$. Vaginalis \\
\hline $\begin{array}{l}\text { Wet mount } \\
\text { preparation }\end{array}$ & 15 & 85 \\
\hline
\end{tabular}

Table.4 Age Group Correlation with Parasitic STD

\begin{tabular}{|l|c|c|c|}
\hline S.No & Age & Positive for T.vaginalis & $\begin{array}{c}\text { Positive for } \\
\text { Bacterial vaginitis }\end{array}$ \\
\hline 1 & $20-30$ & 21 & 23 \\
\hline 2 & $31-40$ & 6 & 16 \\
\hline 3 & $41-50$ & 3 & 8 \\
\hline 4 & 50 and above & - & 7 \\
\hline
\end{tabular}


Table.5 Microbial Profile of Vaginal Swab

\begin{tabular}{|l|c|c|c|c|c|}
\hline S.No & Age & $\begin{array}{c}\text { No.of Bacterial } \\
\text { vaginitis positive }\end{array}$ & $\begin{array}{c}\text { No.of T. vaginalis } \\
\text { positive }\end{array}$ & $\begin{array}{c}\text { No. of fungal } \\
\text { vaginitis positive }\end{array}$ & $\begin{array}{c}\text { No. of Normal } \\
\text { vaginal flora }\end{array}$ \\
\hline 1 & $20-30$ & 23 & 21 & 1 & 8 \\
\hline 2 & $31-40$ & 16 & 6 & 1 & 5 \\
\hline 3 & $41-50$ & 8 & 3 & - & 1 \\
\hline 4 & $50 \&$ \\
above & 7 & 54 & 30 & 2 & - \\
\hline & & & & & \\
\hline
\end{tabular}

Table.6 Isolation Rates of Bacteria in Vaginal Swab

\begin{tabular}{|l|l|l|l|l|l|l|l|}
\hline \multirow{2}{*}{ S.No } & \multirow{2}{*}{ Name of the bacterial isolate } & \multicolumn{6}{|c|}{ Sensitivity Pattern } \\
\cline { 3 - 8 } & & $\begin{array}{c}\mathrm{Imi}(\mathrm{S}) \\
\%\end{array}$ & $\begin{array}{c}\mathrm{Ak}(\mathrm{S}) \\
\%\end{array}$ & $\begin{array}{c}\mathrm{G}(\mathrm{S}) \\
\%\end{array}$ & $\begin{array}{c}\mathrm{Cz}(\mathrm{S}) \\
\%\end{array}$ & $\begin{array}{c}\mathrm{Ca}(\mathrm{S}) \\
\%\end{array}$ & $\begin{array}{c}\mathrm{Ce}(\mathrm{S}) \\
\%\end{array}$ \\
\hline 1 & Escherichia coli (19) & 100 & 100 & 100 & 0 & 20 & 26 \\
\hline 2 & Klebsiella oxytoca (12) & 100 & 100 & 100 & 0 & 20 & 26 \\
\hline 3 & Klebsiella pneumonia (10) & 100 & 100 & 100 & 0 & 20 & 26 \\
\hline 4 & Pseudomonas aeruginosa (5) & 100 & 100 & 94 & 0 & 15 & 22 \\
\hline 5 & Acinetobacter baumanii (2) & 100 & 100 & 90 & 0 & 10 & 20 \\
\hline 6 & $\begin{array}{l}\text { Staphylococcus epidermidis } \\
\text { (2) }\end{array}$ & - & 90 & 100 & 10 & 100 & 100 \\
\hline
\end{tabular}

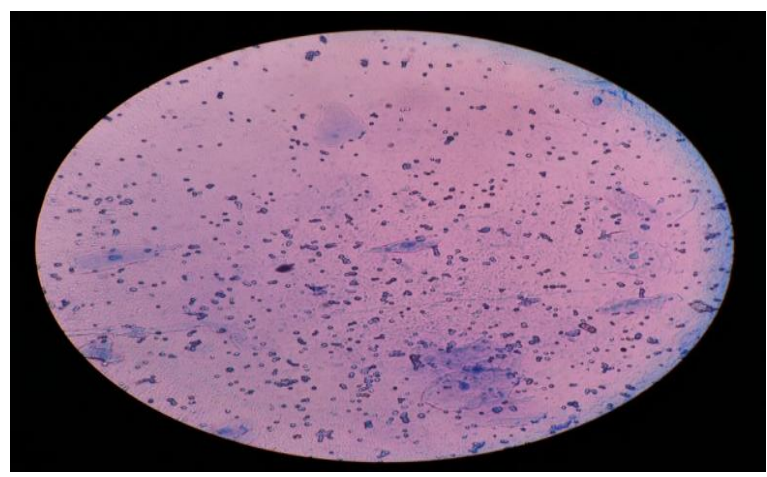

The analysis of the vaginal discharge with patients attending our OG department, gave rise to a wide range of microbial profile including bacterial, parasitic and fungal agents. About $54 \%$ of the samples had bacterial culture positivity, in which Escherichia coli was $39 \%$ positive (20/54) samples, Klebsiella oxytoca contributed for
24\% with 13 samples, and Klebsiella pneumoniae had a share of $19 \%$ with (10/54) samples, the other isolates were Pseudomonas aeruginosa which was isolated from 5 samples contributing for $10 \%$ positivity and Acinetobacter baumanii and Staphylococcus epidermidis $4 \%$ with $(2 / 54)$ samples in each. These bacterial 
isolates were found in the vaginal swabs due to the lack of personal hygiene, as majority of our patients come from low socio economic stata, with paddy field work pattern. which would have enhanced the colonization of this organism from the large intestine.

The next important isolate was parasitic agent Trichomonas vaginalis which contributed for $30 \%$, was responsible for green coloured foul-smelling discharge, itching in vagina \& vulva. It is the major sexually transmitted non-viral, nonbacterial disease, present all over the world.

It inhabits the genetalia, urinary tract in female, urethra and prostate in male. It takes shelter and nutrition from another living organism causing vulvo-vaginitis, PID. It can also precipitate infertility and sterility.

Kupferburg Media was selected as it contains selective agent to inhibit the growth of GNB \& GPC. In addition it contains nitrogenous compounds for ensuring the growth of Trichomonas vaginalis. The inclusion of $0.1 \%$ agar reduces the oxygen tension for the prolific growth of Trichomonas vaginalis. Our study shows $30 \%$ of the samples were positive for Trichomonas vaginalis (Table: 2 ).

The sensitivity pattern of the gram negative bacilli showed $100 \%$ sensitivity to Imipenem, Amikacin and Gentamycin. 100\% resistant for Cefazolin, $80 \%$ for Ceftazidime and $74 \%$ for Cefotaxime.

The analysis of Gram positive cocci (Staphylococcus epidermidis), had the following pattern, $100 \%$ oxacillin, linezolid and vancomycin sensitive. It had 50\% resistant to Gentamycin and Ampicillin.

Other than the bacterial, parasitic agents, the study also showed the presence of fungal agent in the sample- Candida albicans (2/100) with 2\%. This also may be associated with sexual transmission similar to Trichomonas vaginalis.

In conclusion, the present study reveals that the vagina of the reproductive age group female gets inhabited with a variety of microorganisms due to faulty hygienic habits, which enhances migration of bacteria from intestine to genital tract.

Coitus is another precipitating factor for vaginitis which aids in the parasitic, fungal vaginitis. As an health professional it is mandatory to give health education to the patients with regards to personal hygienic habits and safe coitus in order to prevent vaginitis from happening in young reproductive ladies as shown in our studies.

This analysis shows the correlation between bacterial and parasitic isolation, which was more common among sexually active female patients as shown in our study, which requires screening of patients in appropriate manner and treat accordingly to envisage a healthy quality life for the patients.

\section{References}

1. Koneman's. Colour Atlas and Textbook of Diagnostic Microbiology, 6th Edition, 88-90 P.

2. Lucia Pattullo, Sarah Griffeth, Lili Ding et al. Stepwise Diagnosis of Trichomonas vaginalis Infection in Adolescent Women. J. Clin. Microbiol 2009; 47: 59-63.

3. E. D. Jatau, O. S. Olonitola and A. T. Olayinka. Prevalence of Trichomonas Infeection among Women Attending Antenatal Clinics in Zaria, Nigeria. Annals of African Medicine 2006; 5: 178-181. 
4. Nashaat E. Nassel, Amera F. Afif et al. Evaluation of microscopy and polymerase chain reaction for diagnosis of symptomatic and asymptomatic female Trichomoniasis. Egyptian Parasitologists United Society Journal 2014; 7: 37-46.

5. National committee for clinical Laboratory Standards. Abbreviated identification of Bacteria and Yeast; Approved Guidelines. NCCLS document M35-A. Wayne, PA: NCCLS, 2002.
6. Z. T. Valadkhani, M. Assmar, N. Hassan et al. The Prevalence of Trichomoniasis in High-Risk Behavior Women Attending the Clinics of Tehran Province Penitentiaries. Iran J Med Sci 2010; 35(3) :190-194.

7. Shamim Mumtaz, Mumtaz Azhmed et al. Aerobic vaginal Pathogens and Their Sensitivity Pattern. J Ayub Med Coll Abbottabad 2008; 20(1): 113-117.

\section{How to cite this article:}

Karthika Jayakumar, Wills shiela, S. Jayalakshmi, Sathya Pandurangan and M. Mohanambal. 2016. Microbial Vaginitis in Reproductive Women of Silk city of South India. Int.J.Curr.Microbiol.App.Sci.5(2): 272-278. doi: http://dx.doi.org/10.20546/ijcmas.2016.502.031 